\title{
Review of electrical stimulation, botulinum toxin, and their combination for spastic drop foot
}

\author{
Ari Jacob Levi Wilkenfeld, MD, PhD \\ Department of Neurology, Department of Veterans Affairs Boston Medical Center; Department of Neurology, Boston \\ University School of Medicine; and Department of Neurology, Harvard University School of Medicine, Boston, MA
}

\begin{abstract}
Spastic drop foot is a functional impairment causing significant morbidity and mortality. Multiple treatments are available for this condition, but it is often not clear which treatment or combination of treatments is optimal for a given patient. One relatively recent therapy is the use of functional electrical stimulation to stimulate the peroneal nerve. Another is the use of botulinum toxin injections in the spastic ankle plantar flexors. While reasons exist to think these two treatments might work effectively in combination, there is no clear consensus in the literature. In this article, I review the background of the pathophysiology of spastic drop foot and its treatment options. I present some of the theoretical reasons why functional electrical stimulation and botulinum toxin injections could work synergistically and present a literature review on the topic. Recommendations for future research are discussed.
\end{abstract}

Key words: ankle, botulinum toxins, chemodenervation, drop foot, functional electrical stimulation, gait, muscle spasticity, neurorehabilitation, peroneal nerve stimulation, upper motor neuron syndrome.

\section{SPASTIC DROP FOOT}

Spastic drop foot is a functional impairment causing significant morbidity by impairing gait, limiting activities of daily living, and contributing to injuries [1]. Spastic drop foot exists when, due to a combination of weakness of the ankle dorsiflexors (primarily tibialis anterior) and spasticity of the ankle plantar flexors (primarily gastrocnemius and soleus), the ankle has a predisposition for staying pathologically plantar flexed. Due to associated weakness of ankle evertors (e.g., peroneal musculature) and/or spasticity of invertors (e.g., tibialis posterior), pathological foot inversion is also often associated [2-3].

Because ankle dorsiflexion during the swing phase of gait is essential for foot clearance, drop foot can lead to falls and injury [1]. In addition, with drop foot, foot-floor contact in stance phase can happen initially at the forefoot (as opposed to at the heel in nondisabled gait) and limited dorsiflexion can prevent forward progression of the tibia, resulting in hyperextension of the knee and limited forward translation of the body [4]. Those affected often develop pathological compensatory gaits to attempt to compensate for spastic drop foot. One of these, referred to as "steppage gait," involves abnormally flexing the hip and bending the knee to attempt to get the foot to clear the ground [5]. Other patients will hike their hip on the side of the spastic ankle with each swing phase or circumduct the lower limb to aid in foot clearance [6].

Abbreviations: $\mathrm{AAN}=$ American Academy of Neurology, $\mathrm{AFO}=$ ankle-foot orthosis, $\mathrm{BTA}=$ botulinum toxin type $\mathrm{A}$, $\mathrm{BTB}=$ botulinum toxin type $\mathrm{B}, \mathrm{BTX}=$ botulinum toxin, $\mathrm{CMAP}=$ compound muscle action potential, $\mathrm{CNS}=$ central nervous system, $\mathrm{FES}=$ functional electrical stimulation, $\mathrm{MS}=$ multiple sclerosis, $\mathrm{PNS}=$ peroneal nerve stimulation, $\mathrm{SCI}=$ spinal cord injury, TBI = traumatic brain injury, UMNS = upper motor neuron syndrome, VA = Department of Veterans Affairs.

Address all correspondence to Ari Jacob Levi Wilkenfeld, MD, PhD. Email: awilkenfeld@alum.mit.edu

http://dx.doi.org/10.1682/JRRD.2012.03.0044 
The increased effort required can lead to slow, tiring, and unsafe gait [6-7].

Aside from the issues with gait, in severe cases, spastic drop foot can make it difficult for patients to transfer, even with help from their caregivers, by denying them a stable pivot point on the ground. Also, abnormality of ankle posture can lead to painful pressure points within the shoe (or against the mattress), leading to skin breakdown [4]. Spasticity can be extremely painful for patients, and abnormal positioning can cause nerve, bone, and joint damage [4]. Furthermore, muscles being immobilized in a shortened position can lead to loss of muscle sarcomeres and buildup of connective tissues [8]. Finally, evidence exists that beyond the pathology caused by immobilization, spasticity can actually increase the long-term stiffness of muscle by increased actin-myosin interdigitation. Eventually, contracture of the joint can result [9].

Spastic drop foot is a problem caused by multiple neurological conditions that lead to upper motor neuron syndrome (UMNS), including stroke, traumatic brain injury (TBI), multiple sclerosis (MS), and spinal cord injury (SCI) [10]. The literature reports that of those who have had a stroke, a conservative estimate is that 20 percent experience spastic drop foot [11]. It has been further approximated in the literature that 75 percent of patients with severe TBI and 60 percent of patients with moderate to severe MS require treatment for spasticity, its complications, or both [12]. Also, 65-78 percent of patients with chronic SCI have symptoms of spasticity [13].

\section{SPASTICITY}

Spasticity, itself, is difficult to define and the exact character of spasticity is of much debate in the literature. An often-used definition is that of Lance in 1980: "Spasticity is a motor disorder that is characterized by a velocity dependent increase in the tonic stretch reflex with exaggerated tendon reflexes, resulting from the hyperexcitability of the stretch reflex, as one component of the [UMNS]" [14-15]. This definition, however, is only one facet of the constellation of involuntary motor activity in UMNS [16-17]. For example, it does not fully address the effects on tone during active function, as in when one is trying to activate a spastic muscle's antagonist. These effects may be related to the stretch reflex, but could also be influenced by abnormal neural connectivity within the central nervous system (CNS).
Spasticity has several different manifestations not solely related to the stretch reflex. Tonic muscle contraction without volitional command with a superimposed stretch sensitivity was coined "spastic dystonia" by Denny-Brown in 1966 [16-18]. The phenomenon of pathological activation of agonist and antagonist from inappropriate surpraspinal commands combined with stretch sensitivity has been referred to as "spastic cocontraction" [16-17]. This may be the case in spastic drop foot if plantar flexors are activating at the same time as the patient tries to voluntarily activate dorsiflexion. Spastic cocontraction can lead patients to move slowly and with great effort [16].

Furthermore, spasticity is known to be a heterogeneous condition. There exist, for example, both "spinal" and "cerebral" models of spasticity [19]. Clinically, cerebral, or "hemiplegic," spasticity tends to involve stereotypical postures involving flexion of the upper limbs and extension of the lower limbs. Spasticity of spinal origin can be similar but tends to involve more flexor spasms of the lower limbs. Stefanovska et al. divided spasticity into "tonic" and "phasic" components [20-21], depending on whether sensitivity to velocity or length of stretch increased. Study of spasticity in general is also complicated by the fact that both involvement of different descending tracts [22] and the amount of time after an upper motor neuron lesion [11] can influence the nature of the deficit and the response to therapy.

To attempt to clarify the definition of spasticity, Burridge et al. proposed the following: "[Spasticity is] disordered sensorimotor control, resulting from an upper motor neuron lesion, presenting as intermittent or sustained involuntary activation of muscles" [23]. Of note, both this definition and Lance's stress that spasticity exists in the context of UMNS. This is important because the negative symptoms of UMNS, i.e., weakness and discoordination, are often difficult to functionally disentangle from the positive symptoms, including spasticity.

The most commonly used biomechanical measure of spasticity clinically is the Modified Ashworth Scale (Figure 1), a $0-4$ ordinal scale that represents resistance to passive movement on physical examination. While this has been shown to have reasonable interrater reliability, it has been very difficult to show correlation with functional outcomes [24]. Likewise, it can be influenced by other, nonneurogenic causes of increased tone, such as soft tissue contractures [23]. 


\section{0 = Normal tone \\ 1 = Slight "catch" \\ $1+$ = Significant "catch" \\ 2 = Mild, limb moves easily \\ 3 = Moderate, passive range of movement difficult \\ 4 = Severe, rigid limb}

Figure 1.

Modified Ashworth Scale [24].

It is not clear what causes spasticity in UMNS [17], although many hypotheses have been proposed in the literature. Two possibilities include the sprouting and regrowth of terminal excitatory axons onto areas of motor neuron dendrites that are bare secondary to degeneration of descending fibers and denervation hypersensitivity of the bare dendritic membranes. These mechanisms could potentially explain the gradual development of spasticity seen in UMNS [25]. The loss of presynaptic [25-26], recurrent, and/or reciprocal inhibition of motor neurons could also be related to increased spinal reflexes [25].

\section{TREATMENT}

Because both upper motor neuron weakness and increased tone in the form of spasticity contribute to spastic drop foot, it can be difficult to determine the optimal treatment, both in the setting of acute rehabilitation and when assessing for assistive technology for chronic disability. Traditional treatment modalities include use of an ankle-foot orthosis (AFO), physical therapy, systemic medication, tendon surgery, and/or focal alcohol neurolysis. More recent treatment options include botulinum toxin (BTX) injections and functional electrical stimulation (FES).

Conventional mechanical treatment for drop foot in any form often utilizes an AFO to hold the foot mechanically in dorsiflexion [6,27-28]. This can assist with toe clearance during the swing phase of gait [28]. AFOs commonly used for spastic drop foot hold the ankle at a generally constant angle, with variable amounts of compliance about that point. AFOs have the disadvantage that they can be poorly tolerated by patients $[27,29]$, can lead to pressure sore formation [28], and can make it difficult to generate a standing torque from a seated position or to climb stairs.

For patients with ankle spasticity as well as weakness, stretching by physical therapy can be utilized, sometimes combined with serial casting [30]. This can be an important component of treatment, especially if there is a component of soft tissue contracture in addition to spasticity. Dynamic splinting or splints with built-in mechanical stretching are also used at times as an alternative to serial casting [31]. In severe cases of contracture, surgical resection is sometimes considered [32]. More recently, there have been some investigations into the design of powered ankle orthoses [33], but these are limited by weight and battery life and, further, do not necessarily give exercise benefit to the weak dorsiflexors because the torque is being applied externally.

A range of general pharmacologic treatments for spasticity exist. The most commonly used clinically are baclofen, a structural analog of GABA (gamma-aminobutyric acid); tizanadine, which binds to central alpha2adrenergic receptors; dantrolene, a direct muscle relaxant; and benzodiazepines. The general downside of these medications is their side effect profiles, which often become intolerable before they achieve their therapeutic goal. These side effects include weakness, fatigue and, in the case of benzodiazepines in particular, the risk of dependence [34]. For some patients with severe general spasticity, an implanted pump that delivers baclofen directly through a catheter to the CNS can be effective, especially in combination with other modalities [35].

Phenol or other alcohol injections are well-known focal treatments for spasticity. Neurolysis using alcohol will generally weaken a muscle for months to over a year and can weaken large and powerful spastic muscle groups [36]. Until the advent of BTX therapy, this was the major focal intervention available. The major drawbacks are the risks of dysesthesia, which limits the technique primarily to mostly pure motor nerves, and the relative irreversibility of the process.

The other major treatments for spastic drop foot are FES and BTX injections, either separately or in concert. These will be discussed separately in the following sections, followed by a review of the combination of the two therapies. 


\section{Functional Electrical Stimulation}

FES is the method of using electric current to activate muscles and nerves that are weak or paralyzed because of a lack of descending commands (upper motor neuron damage) but still have intact lower motor neurons and musculature. It has been investigated in a variety of clinical situations, including upper- and lower-limb weakness, bladder dysfunction, diaphragmatic dysfunction [37], and postural control [38].

FES using peroneal nerve stimulation (PNS) has been investigated for the treatment of spastic drop foot from upper motor neuron injuries [11,27]. These devices cause dorsiflexion and eversion of the ankle by surface stimulation of the peroneal nerve. PNS in paraplegia from SCI has also been shown to aid gait by generating a knee/hip withdrawal reflex [37], although the effects on these joints in MS seem less clear [39]. Although there has been some investigation into percutaneous and implanted systems [20-21,40], surface FES systems are widely available and have fewer contraindications. PNS has been investigated both for its potential gait improvement while the patient is actively using the device, the "orthotic effect," [41] and for its rehabilitation benefit after the device is no longer in use, the "therapeutic effect." [42]

At least three PNS systems have been used [11,4344]. These systems use surface electrodes over the peroneal nerve to activate the musculature and a sensor to determine when the leg is in swing phase and in need of stimulation to activate dorsiflexion. Two of the current designs, the Odstock ${ }^{\circledR}$ (Odstock Medical Limited; Salisbury, Wiltshire, UK) and NESS L300 ${ }^{\circledR}$ (Bioness Inc; Valencia, California) utilize a force sensor inserted into the patient's shoe to determine when swing phase begins, while a third, the WalkAide ${ }^{\circledR}$ (Innovative Neurotronics; Austin, Texas), utilizes a leg-tilt sensor to detect state changes in gait. Some units come with a cuff that fastens around the calf (Figure 2). These cuffs can have two electrodes that are positioned by the therapist, with one placed over the origin of the tibialis anterior muscle and the other placed over the common peroneal nerve posterior and proximal to the fibular head. The therapist adjusts the placement of the electrodes and the stimulation parameters. After the placement is optimized, the electrodes are fixed in the cuff so patients do not have to adjust them daily when they put on the device.

Previous studies have compared the utility of PNS for drop foot from UMNS with other treatments. Granat

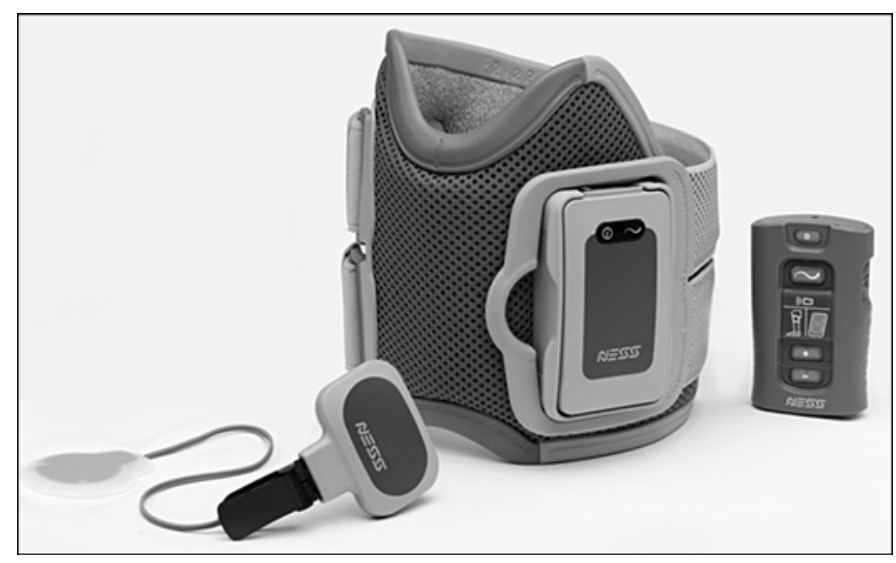

\section{Figure 2.}

NESS $L 300^{\circledR}$ with electrode cuff, force-sensitive shoe insert, and programmer. Photo courtesy of Bioness Inc (Valencia, California).

et al. compared PNS with physiotherapy in a crossover trial with 17 poststroke patients with hemiplegia and spastic drop foot [42]. There was no control using an AFO, which is generally the standard of care for the condition [27], and no randomization. They showed no consistent increase in speed (over 6-10 m) for PNS.

Ring et al. attempted to compare PNS with AFO in 15 patients with MS; however, they did not separate out the two treatments for the practice periods, instead testing gait after 4 weeks of daily combined PNS/AFO use and again after an additional 4 weeks of pure PNS use [45]. The treatment periods were also not randomized. They found improvement in gait symmetry but not gait speed for the PNS compared with the AFO. Van Swigchem et al. replaced the AFO in 26 chronic stroke patients with PNS and tested activity level and $10 \mathrm{~m}$ comfortable walking speed after 2 and 8 weeks [29]. There was no randomization of treatment order and no standardization of orthoses. The AFO and PNS were equally effective in regard to walking speed and activity level but the subjects expressed a preference for the PNS.

Burridge et al. compared PNS with physiotherapy to physiotherapy alone in a randomized control trial of stroke patients [6]. Use of an AFO in the control group was not specified. A greater increase in gait speed (measured over $10 \mathrm{~m}$ ) was seen in the PNS group $(20.5 \%)$ when they walked using the stimulator (orthotic effect) than the physiotherapy-alone group $(5.2 \%)$ but no improvement was seen in the PNS group when they walked without using the stimulator (no therapeutic effect). 
Finally, Sheffler et al. tested 14 chronic stroke patients with an AFO and PNS and measured their gait using the modified Emory Functional Ambulation Profile [27]. Each subject used both devices and had only 2 days to train with the PNS. The authors found comparable results between AFO and PNS but noted that this may have been because of the lack of a training period for the PNS. Patients expressed a preference for PNS for longterm use.

\section{Botulinum Toxin}

BTX is a protein that exists in seven serotypes produced by the bacterium botulinum clostridium. All serotypes act on the same target organs and produce similar effects [46]. The primary mechanism of BTX is to prevent the release of acetylcholine at the presynaptic terminal, thus impairing neuromuscular transmission and inducing weakness. The different serotypes interfere in different parts of the process. BTX type A (BTA) cleaves synaptosomal-associated protein-25 whereas BTX type B (BTB) cleaves vesicle-associated membrane protein [47]. Focal weakness from the use of BTX can start to be seen within 2-3 days of injection [48]. The effect typically peaks at approximately 4 to 6 weeks postinjection and wanes after approximately 3 months [49]. There is evidence that the effect wears off both as a result of axon sprouting and eventual return of function to the original terminals [47]. Two of the serotypes in four preparations have become available in the United States. BTA is available as onabotulinumtoxinA (trade name Botox ${ }^{\circledR}$ ), abobotulinumtoxin $A$ (trade name Dysport ${ }^{\mathbb{B}}$ ), and incobotulinumtoxin $A$ (trade name Xeomin ${ }^{\circledR}$ ). BTB is available as rimabotulinumtoxinB (trade name Myobloc ${ }^{\circledR}$ ).

BTX injections are considered generally safe and well tolerated [50]. There are three major types of adverse reactions from BTX injection. The first involves lack of function, sometimes secondary to antibody formation against the medication [48]. At least partially because of this, there are guidelines against dosing BTX more frequently than once every 3 months. The second adverse effect is weakness in the injected muscles. This is not truly an adverse effect because it is the primary effect of the medication; however, it can cause morbidity if, for instance, a clinician overly weakens a muscle that the patient requires for postural support. The third major type of adverse reaction involves weakening of muscles remote from the point of injection. Electrophysiological studies have shown increased jitter at points remote from
BTX injection as well [48]. Postmarketing reports have included rare cases of severe effects thought to be associated with spread of toxin, including respiratory depression [51].

Despite the fact that none of the preparations of BTX are Food and Drug Administration-approved in the United States for lower-limb spasticity (onabotulinumtoxinA was recently approved for upper-limb spasticity), many clinicians have for some time considered BTX injections to be a standard of care for focal spasticity [46,52]. Also, it was recommended for the reduction of tone by the 2008 American Academy of Neurology (AAN) Practice Parameter [46]. An established procedure for drop foot is to inject into the gastrocnemius/soleus and/or tibialis posterior [11,46,53-59]. This has been proposed as helpful in preventing "pistoning" out of the brace, improving forward tibial progression in stance, preventing skin breakdown, and reducing pain. BTX has been shown to decrease muscle tone in several conditions, but showing when and if it provides functional gait benefits in lowerlimb spasticity has proven extremely difficult [60]. The 2008 AAN Practice Parameter on use of BTX in spasticity concluded that BTX "is established as effective in the treatment of adult spasticity in the upper and lower limb in reducing muscle tone and improving passive function" but that "[t]here are no controlled studies comparing [BTX] to other treatment modalities for spasticity. There is also a need to confirm efficacy for active function in controlled trials" [46]. In part, this may be because of studies that have documented the decrease in spasticity as measured by the Modified Ashworth Scale rather than clinical gait parameters.

Richardson et al. in a blinded, randomized control trial studied the effect of BTA (onabotulinumtoxinA) injections on 52 subjects with heterogeneous conditions including TBI, stroke, SCI, cerebral palsy, tumor, and anoxic injuries [57]. The subjects all had some form of spasticity affecting either the upper or lower limbs. Subjects were randomized to either BTA injections, with dosing and muscles chosen by the provider, or saline injection. The primary outcome measure of the study was decreased tone, and the aggregate results did show a significant decrease in the Modified Ashworth Scale for subjects treated with BTX. A smaller subset of patients who were able to ambulate and were treated in the lower limb were also tested with a $10 \mathrm{~m}$ timed walk, and no significant difference was noted between the treatment and control groups. 
Pittock et al. studied 234 stroke patients with spastic drop foot using either placebo or one of three doses of BTA (abobotulinumtoxinA) [58]. The primary measures of 2-minute walking distance and steppage rate did not significantly differ. There were small but significant improvements in calf spasticity, limb pain, and the need for walking aids. There were similar numbers of adverse reactions in the treatment and nontreatment groups.

Burbaud et al., in a randomized double-blind crossover study, examined 23 hemiparetic patients with ankle plantar flexor and invertor spasticity [59]. Subjects were injected with either BTA (abobotulinumtoxinA) or placebo and then switched to the other after 90 days. In this study, there was a slight increase in gait speed in the treated group, but it was not statistically significant.

Hesse and colleagues examined 12 subjects with chronic spastic hemiplegia from stroke [56]. All subjects were injected with BTA (onabotulinumtoxinA). When measured 4 weeks postinjection, 9 of the 12 subjects had improved gait speed, less premature activation of calf muscles during gait, and reduced calf muscle spasticity. The other 3 did not benefit. There was, however, no control arm in the study.

Mancini et al. ran a double-blind dosing study for spastic drop foot using the onabotulinumtoxinA formulation of BTA [53]. Forty-five spastic feet were allocated to one of three groups with different onabotulinumtoxinA doses for each injected muscle in the three groups. The treating clinician could choose which muscles to inject at the predetermined doses. The average total doses given in the three groups were $167 \mathrm{U}, 322 \mathrm{U}$, and $540 \mathrm{U}$, respectively. Several outcome measures were evaluated covering muscle tone, pain, and gait assessment. All the groups showed significant improvements. The groups using $322 \mathrm{U}$ and $540 \mathrm{U}$ on average did better than the group with $167 \mathrm{U}$; however, the group receiving $540 \mathrm{U}$ on average had an increased incidence of adverse reactions. Of the group receiving $322 \mathrm{U}$ on average, the three most commonly selected injections were the medial gastrocnemius, the lateral gastrocnemius, and the tibialis posterior.

\section{Combined Functional Electrical Stimulation and Botulinum Toxin Injections}

There are reasons to suspect a synergistic effect between electrical stimulation and BTX injection. Such an effect would have two major advantages. Firstly, although BTX has several advantages over the older phe- nol injections (reversibility, lack of dysesthesias, ease of titration and administration), it is also significantly more expensive (several thousand dollars per treatment for some patients). Its primary advantage, that it is reversible, also leads to the cost being magnified because the injections often need to be repeated every 3 to 4 months. If, as is hypothesized, electrical stimulation would increase the efficacy of BTX, the required dose for a given patient could potentially be decreased and, hence, the cost, potentially opening up the treatment to more people who would benefit from it. Secondly, if indeed the required dose was decreased, there is hope that it would also decrease the possibility of adverse reactions, thus enhancing patient safety.

There are effectively four mechanisms by which electrical stimulation might increase the antispasticity effect of BTX. First, animal experiments [54,61-62] have shown that the paralytic effect of BTX starts earlier when the toxin uptake is increased with electrical stimulation. This was thought to be secondary to an increase in the activity of the terminal nerve fibers, where the BTX has its biologic effect. This would likely not be a factor in a combination of PNS with BTX in the triceps surae because the muscles being injected are not the same as the muscles being stimulated. It could, however, be a factor if cyclical electrical stimulation is applied to the plantar flexors and dorsiflexors of the ankle immediately after toxin injection.

The second reason to suspect a synergistic effect between electrical stimulation and BTX is the hypothesis that moving the muscle through flexion/extension cycles could help to mechanically spread the toxin. This could potentially be a factor that could increase efficacy when combining BTX with PNS, assuming that the number of mechanical cycles the ankle goes through is increased as a result of the FES device.

The third possible synergy comes from the direct effects of electrical stimulation on tone reduction. The physiologic principle of reciprocal inhibition of an antagonist during activation of an agonist is well known. Alfieri described this effect as it related to the effect of decreased spasticity of a muscle in the setting of electrical stimulation of its antagonist [63]. The utility of FES as a clinical treatment for spasticity is, however, very much an open question, with such basic questions as whether to stimulate a spastic muscle or its antagonist and whether electrical stimulation can actually worsen spasticity still unclear [64]. 
Stefanovska et al. investigated the effects of long-term implanted PNS on passive resistance to joint movements and concluded that while phasic spasticity increases with use, tonic spasticity decreases [21]. The study did not measure joint resistance while the stimulators were active. Thompson et al. looked for reciprocal inhibition of the soleus during stimulation of the peroneal nerve and concluded it was present and generally unchanged between control subjects and subjects with CNS lesions [26]. The study did not, however, measure reciprocal inhibition during gait when multiple muscle contractions could affect the result [65] or at stimulation levels designed to elicit optimized functional dorsiflexion (as is used in clinical PNS systems). Apkarian and Naumann performed a similar set of experiments and also measured reciprocal inhibition of triceps surae during stimulation of the peroneal nerve [66]. Unlike Thompson et al., who found maximal inhibition at approximately $50 \mathrm{~ms}$ poststimulation, Apkarian et al. found maximal inhibition at approximately $150 \mathrm{~ms}$ poststimulation, suggesting that afferent volleys from muscle contraction rather than initial Ia fiber stimulation are responsible for the effect. Apkarian et al.'s research also did not measure triceps surae activation during gait or at stimulation levels optimized for functional dorsiflexion as used with a clinical PNS.

Interestingly, Lo et al. [67], Krause et al. [68], and Van der Salm et al. [69] describe decreased tone from electrical stimulation of spastic muscles themselves, rather than their antagonists, in spastic stroke and SCI patients. Van der Salm et al. noted that while this could be secondary to recurrent inhibition from Renshaw cells, nonneurogenic factors could also be at play, including local blood flow or mechanical factors [69].

The final reason why BTX and electrical stimulation might work better together than individually is the simple mechanical argument. UMNS, as described previously, includes both dorsiflexion weakness and plantar flexion spasticity. There is speculation in the literature that the reason demonstrating a functional benefit from reduced spasticity in gait is difficult is that the negative symptoms of UMNS (i.e., weakness) cause the more prominent difficulties [60]. Likewise, however, even when increasing the dorsiflexion torque (and thus effectively reducing weakness) with FES, that torque is fighting against increased mechanical resistance from the plantar flexors. Addressing both the positive and negative components of UMNS simultaneously could possibly lead to increased functional gains in gait relative to either of them alone.
Several studies have investigated whether there is a synergistic effect between electrical stimulation and BTX injection, with some looking at spastic drop foot in adults [11,54-55,70-72]. The majority of these looked at electrical stimulation of the muscle after BTX injection, but without using the electrical stimulation to aid functional gait as with PNS using FES.

Picelli et al., in a pilot study reported in a letter to the editor, investigated immediate and delayed electrical stimulation after BTX injection [72]. Twenty-four patients with poststroke spasticity received onabotulinumtoxinA into muscles including the biceps brachii and the abductor digiti minimi. The patients were randomized to receive 60 minutes of electrical stimulation over the injected muscles immediately after injection or 30 minutes of stimulation over the injected muscles for 3 days starting the day after injection. Four weeks after injection, the group that received immediate stimulation had decreased average elbow spasticity (on the Modified Ashworth Scale) and decreased average compound muscle action potentials in the abductor digiti minimi. As the authors note, however, the study is limited by its small size and lack of a group receiving only BTX injection without stimulation.

Frasson et al. investigated changes in the compound muscle action potential (CMAP) of the extensor digitorum brevis injected with BTA (abobotulinumtoxinA) with and without a short course of electrical stimulation in 12 paraparetic patients [70]. They used two stimulation frequencies, 4 and $25 \mathrm{~Hz}$, for 30-minute stimulation sessions once a day for 5 days after injection. They determined that the muscles with low-frequency stimulation had greater decreases in CMAP on several, but not all, of the days tested over the course of 30 days after injection. The high-frequency stimulation did not similarly increase the reduction in CMAP. The study did not use FES functionally or measure gait parameters.

Bayram et al. randomized 12 poststroke patients with spastic drop foot to either high-dose BTX injection or low-dose injection with short-term electrical stimulation [54]. Their protocol used brief alternating plantar flexion/ dorsiflexion stimulation after the injection without using the stimulation functionally in gait. They reported no difference between low-dose BTX use with electrical stimulation and high-dose use without electrical stimulation.

Hesse et al. tested 10 subjects with hemiparesis and lower-limb spasticity by treating half of them with BTX injection and the other half with BTX injection plus 
18 half-hour sessions of alternating plantar flexion/dorsiflexion stimulation [55]. This protocol did not utilize the FES during gait for active dorsiflexion. Their results showed improved muscle tone, gait velocity, stride length, and stance and swing symmetry in the subjects treated with BTX and electrical stimulation.

Baricich et al. examined the effects of taping, electrical stimulation, and stretching in 23 patients with chronic hemiplegia with spastic equinus foot who had all been treated with BTX injections in ankle plantar flexor muscles [71]. The patients in the electrical stimulation group received stimulation for 30 minutes a day for 5 days in the muscles injected. They did not receive stimulation of the antagonist (dorsiflexor) muscles or use FES during gait for active dorsiflexion. For outcome measures, the study noted the Modified Ashworth Scale score, passive range of motion at the ankle, muscle action potential of the medial gastrocnemius, and maximum ankle dorsiflexion angle in the stance phase of gait. At the 20-day measurement point (when one might expect BTX to be close to its maximum effect), all groups performed significantly better than before treatment, except for passive range of motion measurements in the stretching group. Comparing the treatment groups with each other showed that the electrical stimulation group improved significantly more than the stretching group on Modified Ashworth Scale scores and decreased in the motor action potential of the medial gastrocnemius. There was no control group not receiving BTX injection or receiving BTX injection without other concurrent modalities.

Finally, Johnson et al. looked at both active PNS with FES and BTX injection in a group of 18 patients with poststroke drop foot [11]. This study compared a group of patients randomized to physiotherapy alone with a second group randomized to BTX injection with and without FES. The group treated with BTX had an increased mean gait speed of $0.04 \mathrm{~m} / \mathrm{s}$ without FES and $0.09 \mathrm{~m} / \mathrm{s}$ with FES. Unfortunately, the study did not have separate groups getting just BTX injections or just FES, making it more difficult to determine the contributions of the different interventions to the improved outcomes. Also, the control groups were not reported to have been given AFOs as part of the protocol, which is generally the default standard of care for the condition [27].

\section{CONCLUSIONS}

Significant work has been done to date suggesting promise for PNS, BTX injections, and the combination of the two for drop foot from UMNS. Unfortunately, however, much is yet to be determined. For PNS, there is a lack of clear data indicating superiority of gait parameters over the much less expensive AFO. In part, this may be because foot drop can be time and fatigue dependent and trials tended to measure gait parameters over a short distance. Patient preference and increase in muscle strength from prolonged use of PNS are other areas that could benefit from further investigation. There is also evidence of decreased spasticity from electrical stimulation, but basic questions, such as whether the stimulation should be over the spastic muscle or its antagonist, how long the effect lasts, and whether it works during gait, need to be clarified. For BTX, there is evidence of decreased tone but evidence is again lacking for improved gait. For the combination of the two therapies, there is evidence that electrical stimulation of a muscle may increase the efficacy of BTX. However, large controlled studies examining the relative effects of BTX, PNS, and the combination of the two are lacking. Given the prevalence and consequences of this condition, I recommend the performance of trials to help clarify these important questions.

\section{ACKNOWLEDGMENTS}

Financial Disclosures: The author has declared that no competing interests exist.

Funding/Support: This material was unfunded at the time of manuscript preparation.

Additional Contributions: I would like to acknowledge the physicians and staff at the Department of Veterans Affairs (VA) Medical Centers in Boston and Cleveland and their colleagues at Boston University School of Medicine, Harvard, and Braintree Rehabilitation Hospital, including Dr. Neil Kowall, Dr. Stephen Koelbel, Dr. Carlos Kase, Dr. Robert Ruff, Dr. Douglas Katz, Dr. Kun Yan, and Dr. Ronald Triolo, who were very supportive during this project. A large portion of the work for this article was done during a VA advanced neurology fellowship at the Boston VA Medical Center.

\section{REFERENCES}

1. Weerdesteyn V, de Niet M, van Duijnhoven HJ, Geurts AC. Falls in individuals with stroke. J Rehabil Res Dev. 2008; 
45(8):1195-1213. [PMID:19235120]

http://dx.doi.org/10.1682/JRRD.2007.09.0145

2. Royal College of Physicians, British Society of Rehabilitation Medicine, Chartered Society of Physiotherapy, Association of Chartered Physiotherapists Interested in Neurology. Spasticity in adults: management using botulinum toxin. National guidelines. London (UK): RCP; 2009.

3. Adams J, Perry J. Gait analysis: Clinical application. In: Rose J, Gamble J, editors. Human walking. Baltimore (MD): Williams and Wilkins; 1994.

4. Mayer N, Esquenazi A, Childers M. Common patterns of clinical motor dysfunction. In: Brashear A, Mayer N, editors. Spasticity and other forms of muscle overactivity in the upper motor neuron syndrome. Bronx (NY): We Move; 2008. p. 27-38.

5. Springhouse Corporation. Professional guide to signs and symptoms. 5th ed. Springhouse (PA): Springhouse Corporation/Lippincott Williams \& Wilkins; 2006.

6. Burridge JH, Taylor PN, Hagan SA, Wood DE, Swain ID. The effects of common peroneal stimulation on the effort and speed of walking: a randomized controlled trial with chronic hemiplegic patients. Clin Rehabil. 1997;11(3):201-10. [PMID:9360032] http://dx.doi.org/10.1177/026921559701100303

7. Chen G, Patten C, Kothari DH, Zajac FE. Gait differences between individuals with post-stroke hemiparesis and nondisabled controls at matched speeds. Gait Posture. 2005; 22(1):51-56. [PMID:15996592] http://dx.doi.org/10.1016/j.gaitpost.2004.06.009

8. Williams PE, Catanese T, Lucey EG, Goldspink G. The importance of stretch and contractile activity in the prevention of connective tissue accumulation in muscle. J Anat. 1988;158:109-14. [PMID:3225214]

9. Gracies JM. Pathophysiology of spastic paresis. I: Paresis and soft tissue changes. Muscle Nerve. 2005;31(5):535-51. [PMID:15714510] http://dx.doi.org/10.1002/mus.20284

10. Taylor PN, Burridge JH, Dunkerley AL, Wood DE, Norton JA, Singleton C, Swain ID. Clinical use of the Odstock dropped foot stimulator: its effect on the speed and effort of walking. Arch Phys Med Rehabil. 1999;80(12):1577-83. [PMID:10597809] http://dx.doi.org/10.1016/S0003-9993(99)90333-7

11. Johnson CA, Burridge JH, Strike PW, Wood DE, Swain ID. The effect of combined use of botulinum toxin type A and functional electric stimulation in the treatment of spastic drop foot after stroke: a preliminary investigation. Arch Phys Med Rehabil. 2004;85(6):902-9. [PMID:15179643] http://dx.doi.org/10.1016/j.apmr.2003.08.081

12. Barnes MP, Bhakta BB, Moore P, Richardson D, Salisbury C, Thornton H, Turner-Stokes L, Ward A. The management of adults with spasticity using botulinum toxin: a guide to clinical practice. Byfleet, Surrey (UK): Radius Healthcare; 2001.

13. Adams MM, Hicks AL. Spasticity after spinal cord injury. Spinal Cord. 2005;43(10):577-86. [PMID:15838527] http://dx.doi.org/10.1038/sj.sc.3101757

14. Lance J. Symposium synopsis. In: Feldman RG, Young RR, Koella WP, editors. Spasticity: Disordered motor control. Chicago (IL): Year Book Medical; 1980. p. 485-94.

15. Wood DE, Burridge JH, van Wijck FM, McFadden C, Hitchcock RA, Pandyan AD, Haugh A, Salazar-Torres JJ, Swain ID. Biomechanical approaches applied to the lower and upper limb for the measurement of spasticity: a systematic review of the literature. Disabil Rehabil. 2005; 27(1-2):19-32. [PMID:15799142] http://dx.doi.org/10.1080/09638280400014683

16. Mayer N, Herman R. Positive signs and consequences of an upper motor neuron syndrome. In: Brashear A, Mayer $\mathrm{N}$, editors. Spasticity and other forms of muscle overactivity in the upper motor neuron syndrome. Bronx (NY): We Move; 2008. p. 11-26.

17. Gracies JM. Pathophysiology of spastic paresis. II: Emergence of muscle overactivity. Muscle Nerve. 2005;31(5): 552-71. [PMID:15714511] http://dx.doi.org/10.1002/mus.20285

18. Denny-Brown D. The cerebral control of movement. Liverpool (UK): University Press; 1966.

19. Mayer N. Clinicophysiologic concepts of spasticity and motor dysfunction in adults with an upper motor neuron lesion. In: Mayer N, Simpson D. Spasticity. Etiology, evaluation, management, and the role of botulinum toxin. Bronx (NY): We Move; 2002. p. 1-10.

20. Stefanovska A, Gros N, Vodovnik L, Rebersek S, Acimović-Janezic R. Chronic electrical stimulation for the modification of spasticity in hemiplegic patients. Scand J Rehabil Med Suppl. 1988;17:115-21. [PMID:3261039]

21. Stefanovska A, Vodovnik L, Gros N, Rebersek S, Acimović-Janezic R. FES and spasticity. IEEE Trans Biomed Eng. 1989;36(7):738-45. [PMID:2787282] http://dx.doi.org/10.1109/10.32106

22. Brown P. Pathophysiology of spasticity. J Neurol Neurosurg Psychiatry. 1994;57(7):773-77. [PMID:8021658] http://dx.doi.org/10.1136/jnnp.57.7.773

23. Burridge JH, Wood DE, Hermens HJ, Voerman GE, Johnson GR, van Wijck F, Platz T, Gregoric M, Hitchcock R, Pandyan AD. Theoretical and methodological considerations in the measurement of spasticity. Disabil Rehabil. 2005;27(1-2):69-80. [PMID:15799144] http://dx.doi.org/10.1080/09638280400014592

24. Bohannon RW, Smith MB. Interrater reliability of a modified Ashworth scale of muscle spasticity. Phys Ther. 1987; 67(2):206-7. [PMID:3809245] 
25. Young RY. Physiology and pharmacology of spasticity. In: Gelber D, Jeffery D, editors. Clinical evaluation and management of spasticity. New York (NY): Humana Press; 2002. p. 3-12.

26. Thompson AK, Estabrooks KL, Chong S, Stein RB. Spinal reflexes in ankle flexor and extensor muscles after chronic central nervous system lesions and functional electrical stimulation. Neurorehabil Neural Repair. 2009;23(2):133-42. [PMID:19023139] http://dx.doi.org/10.1177/1545968308321067

27. Sheffler LR, Hennessey MT, Naples GG, Chae J. Peroneal nerve stimulation versus an ankle foot orthosis for correction of footdrop in stroke: impact on functional ambulation. Neurorehabil Neural Repair. 2006;20(3):355-60. [PMID:16885421] http://dx.doi.org/10.1177/1545968306287925

28. Kogler G. Orthotic management. In: Gelber D, Jeffery D, editors. Clinical evaluation and management of spasticity. New York (NY): Humana Press; 2002. p. 67-93.

29. van Swigchem R, Vloothuis J, den Boer J, Weerdesteyn V, Geurts AC. Is transcutaneous peroneal stimulation beneficial to patients with chronic stroke using an ankle-foot orthosis? A within-subjects study of patients' satisfaction, walking speed and physical activity level. J Rehabil Med. 2010;42(2):117-21. [PMID:20140406] http://dx.doi.org/10.2340/16501977-0489

30. Albany K, Myers R, Hunt D. Physical and occupational therapy considerations in adult patients receiving botulinum toxin injections for muscle overactivity. In: Brashear A, Mayer N, editors. Spasticity and other forms of muscle overactivity in the upper motor neuron syndrome. Bronx (NY): We Move; 2008. p. 219-30.

31. Farmer SE, Woollam PJ, Patrick JH, Roberts AP, Bromwich W. Dynamic orthoses in the management of joint contracture. J Bone Joint Surg Br. 2005;87(3):291-95. http://dx.doi.org/10.1302/0301-620X.87B3.15445

32. Keenan M, McDaid P. Orthopedic interventions for the management of limb deformities in upper motor neuron syndromes. In: Gelber D, Jeffery D, editors. Clinical evaluation and management of spasticity. New York (NY): Humana Press; 2002. p. 197-255.

33. Ferris DP, Czerniecki JM, Hannaford B. An ankle-foot orthosis powered by artificial pneumatic muscles. J Appl Biomech. 2005;21(2):189-97. [PMID:16082019]

34. Gracies J, Elovic E, McGuire J, Nance P, Simpson D. Traditional pharmacological treatments for spasticity. Part II: Systemic treatments. In: Mayer N, Simpson D, editors. Spasticity. Etiology, evaluation, management, and the role of botulinum toxin. Bronx (NY): We Move; 2002. p. 65-93.

35. Saulino M. Intrathecal baclofen therapy for spasticity management: A clinical approach. In: Brashear A, Mayer N, editors. Spasticity and other forms of muscle overactivity in the upper motor neuron syndrome. Bronx (NY): We Move; 2008. p. 231-38.

36. Gracies J, Elovic E, McGuire J, Simpson D. Traditional pharmacological treatments for spasticity. Part I: Local treatments. In: Mayer N, Simpson D, editors. Spasticity. Etiology, evaluation, management, and the role of botulinum toxin. Bronx (NY): We Move; 2002. p. 44-64.

37. Ragnarsson KT. Functional electrical stimulation after spinal cord injury: current use, therapeutic effects and future directions. Spinal Cord. 2008;46(4):255-74.

[PMID:17846639]

http://dx.doi.org/10.1038/sj.sc.3102091

38. Wilkenfeld AJ, Audu ML, Triolo RJ. Feasibility of functional electrical stimulation for control of seated posture after spinal cord injury: A simulation study. J Rehabil Res Dev. 2006;43(2):139-52. [PMID:16847781] http://dx.doi.org/10.1682/JRRD.2005.06.0101

39. Sheffler LR, Bailey SN, Chae J. Spatiotemporal and kinematic effect of peroneal nerve stimulation versus an anklefoot orthosis in patients with multiple sclerosis: a case series. PM R. 2009;1(7):604-11. [PMID:19627953] http://dx.doi.org/10.1016/j.pmrj.2009.04.002

40. Burridge JH, Haugland M, Larsen B, Pickering RM, Svaneborg N, Iversen HK, Christensen PB, Haase J, Brennum J, Sinkjaer T. Phase II trial to evaluate the ActiGait implanted drop-foot stimulator in established hemiplegia. J Rehabil Med. 2007;39(3):212-18. [PMID:17468789] http://dx.doi.org/10.2340/16501977-0039

41. Kottink AI, Oostendorp LJ, Buurke JH, Nene AV, Hermens HJ, IJzerman MJ. The orthotic effect of functional electrical stimulation on the improvement of walking in stroke patients with a dropped foot: a systematic review. Artif Organs. 2004;28(6):577-86. [PMID:15153151] http://dx.doi.org/10.1111/j.1525-1594.2004.07310.x

42. Granat MH, Maxwell DJ, Ferguson AC, Lees KR, Barbenel JC. Peroneal stimulator; evaluation for the correction of spastic drop foot in hemiplegia. Arch Phys Med Rehabil. 1996;77(1):19-24. [PMID:8554468] http://dx.doi.org/10.1016/S0003-9993(96)90214-2

43. Innovative Neurotronics. The WalkAide System for treatment of foot drop [Internet]. Austin (TX): Innovative Neurotronics. Available from: http://www.walkaide.com

44. Bioness Inc. L300 for foot drop [Internet]. Valencia (CA): Bioness Inc. Available from: https://www.bioness.com

45. Ring H, Treger I, Gruendlinger L, Hausdorff JM. Neuroprosthesis for footdrop compared with an ankle-foot orthosis: effects on postural control during walking. J Stroke Cerebrovasc Dis. 2009;18(1):41-47. [PMID:19110144] http://dx.doi.org/10.1016/j.jstrokecerebrovasdis.2008.08.006

46. Simpson DM, Gracies JM, Graham HK, Miyasaki JM, Naumann M, Russman B, Simpson LL, So Y; Therapeutics and technology assessment subcommittee of the American 
Academy of Neurology. Assessment: botulinum neurotoxin for the treatment of spasticity (an evidence-based review): report of the Therapeutics and Technology Assessment Subcommittee of the American Academy of Neurology. Neurology. 2008;70(19):1691-98.[PMID:18458229] http://dx.doi.org/10.1212/01.wnl.0000311391.00944.c4

47. Brin M, Aoki K. Botulinum Toxin Type A: Pharmacology. In: Mayer N, Simpson D, editors. Spasticity. Etiology, evaluation, management, and the role of botulinum toxin. Bronx (NY): We Move; 2002. p. 110-24.

48. Dressler D. Pharmacology of botulinum toxin drugs. In: Brashear A, Mayer N, editors. Spasticity and other forms of muscle overactivity in the upper motor neuron syndrome: Etiology, evaluation, management, and the role of botulinum toxin. Bronx (NY): We Move; 2008. p. 155-62.

49. Comella CL, Jankovic J, Shannon KM, Tsui J, Swenson M, Leurgans S, Fan W; Dystonia Study Group. Comparison of botulinum toxin serotypes A and B for the treatment of cervical dystonia. Neurology. 2005;65(9):1423-29.

[PMID:16275831]

http://dx.doi.org/10.1212/01.wnl.0000183055.81056.5c

50. Schulte-Mattler WJ. Use of botulinum toxin A in adult neurological disorders: efficacy. Tolerability and safety. CNS Drugs. 2008;22(9):725-38.

51. Allergen, Inc. Botox Medication Guide [Internet]. Irvine (CA): Allergen, Inc; Jan 2013. Available from: http://www.allergan.com/assets/pdf/botox pi.pdf

52. Truong DD, Jost WH. Botulinum toxin: clinical use. Parkinsonism Relat Disord. 2006;12(6):331-55.

[PMID:16870487]

http://dx.doi.org/10.1016/j.parkreldis.2006.06.002

53. Mancini F, Sandrini G, Moglia A, Nappi G, Pacchetti C. A randomised, double-blind, dose-ranging study to evaluate efficacy and safety of three doses of botulinum toxin type A (Botox) for the treatment of spastic foot. Neurol Sci. 2005;26(1):26-31. [PMID:15877184] http://dx.doi.org/10.1007/s10072-005-0378-9

54. Bayram S, Sivrioglu K, Karli N, Ozcan O. Low-dose botulinum toxin with short-term electrical stimulation in poststroke spastic drop foot: a preliminary study. Am J Phys Med Rehabil. 2006;85(1):75-81. [PMID:16357552] http://dx.doi.org/10.1097/01.phm.0000193505.85874.61

55. Hesse S, Jahnke MT, Luecke D, Mauritz KH. Short-term electrical stimulation enhances the effectiveness of Botulinum toxin in the treatment of lower limb spasticity in hemiparetic patients. Neurosci Lett. 1995;201(1):37-40. [PMID:8830307] http://dx.doi.org/10.1016/0304-3940(94)12124-9

56. Hesse S, Krajnik J, Luecke D, Jahnke MT, Gregoric M, Mauritz KH. Ankle muscle activity before and after botulinum toxin therapy for lower limb extensor spasticity in chronic hemiparetic patients. Stroke. 1996;27(3):455-60.

\section{[PMID:8610313]}

http://dx.doi.org/10.1161/01.STR.27.3.455

57. Richardson D, Sheean G, Werring D, Desai M, Edwards S, Greenwood R, Thompson A. Evaluating the role of botulinum toxin in the management of focal hypertonia in adults. J Neurol Neurosurg Psychiatry. 2000;69(4):499-506.

[PMID:10990511]

http://dx.doi.org/10.1136/jnnp.69.4.499

58. Pittock SJ, Moore AP, Hardiman O, Ehler E, Kovac M, Bojakowski J, Al Khawaja I, Brozman M, Kanovský P, Skorometz A, Slawek J, Reichel G, Stenner A, Timerbaeva S, Stelmasiak Z, Zifko UA, Bhakta B, Coxon E. A doubleblind randomised placebo-controlled evaluation of three doses of botulinum toxin type A (Dysport) in the treatment of spastic equinovarus deformity after stroke. Cerebrovasc Dis. 2003;15(4):289-300. [PMID:12686794]

http://dx.doi.org/10.1159/000069495

59. Burbaud P, Wiart L, Dubos JL, Gaujard E, Debelleix X, Joseph PA, Mazaux JM, Bioulac B, Barat M, Lagueny A. A randomised, double blind, placebo controlled trial of botulinum toxin in the treatment of spastic foot in hemiparetic patients. J Neurol Neurosurg Psychiatry. 1996;61(3):265-69. [PMID:8795597] http://dx.doi.org/10.1136/jnnp.61.3.265

60. Sheean GL. Botulinum treatment of spasticity: why is it so difficult to show a functional benefit? Curr Opin Neurol. 2001;14(6):771-76. [PMID:11723387] http://dx.doi.org/10.1097/00019052-200112000-00015

61. Simpson LL. Kinetic studies on the interaction between botulinum toxin type A and the cholinergic neuromuscular junction. J Pharmacol Exp Ther. 1980;212(1):16-21. [PMID:6243359]

62. Black JD, Dolly JO. Interaction of 125I-labeled botulinum neurotoxins with nerve terminals. II. Autoradiographic evidence for its uptake into motor nerves by acceptor-mediated endocytosis. J Cell Biol. 1986;103(2):535-44.

[PMID:3015983]

http://dx.doi.org/10.1083/jcb.103.2.535

63. Alfieri V. Electrical treatment of spasticity. Reflex tonic activity in hemiplegic patients and selected specific electrostimulation. Scand J Rehabil Med. 1982;14(4):177-82. [PMID:6983718]

64. Rossi PW. Electrical stimulation. In: Gelber D, Jeffery D, editors. Clinical evaluation and management of spasticity. New York (NY): Humana Press; 2002.

65. Mizuno Y, Tanaka R, Yanagisawa N. Reciprocal group I inhibition on triceps surae motoneurons in man. J Neurophysiol. 1971;34(6):1010-17. [PMID:4329961]

66. Apkarian JA, Naumann S. Stretch reflex inhibition using electrical stimulation in normal subjects and subjects with spasticity. J Biomed Eng. 1991;13(1):67-73. 
JRRD, Volume 50, Number 3, 2013

[PMID:2002676]

http://dx.doi.org/10.1016/0141-5425(91)90047-B

67. Lo HC, Tsai KH, Su FC, Chang GL, Yeh CY. Effects of a functional electrical stimulation-assisted leg-cycling wheelchair on reducing spasticity of patients after stroke. J Rehabil Med. 2009;41(4):242-46. [PMID:19247543] http://dx.doi.org/10.2340/16501977-0320

68. Krause P, Szecsi J, Straube A. Changes in spastic muscle tone increase in patients with spinal cord injury using functional electrical stimulation and passive leg movements. Clin Rehabil. 2008;22(7):627-34. [PMID:18586814] http://dx.doi.org/10.1177/0269215507084648

69. van der Salm A, Veltink PH, Ijzerman MJ, GroothuisOudshoorn KC, Nene AV, Hermens HJ. Comparison of electric stimulation methods for reduction of triceps surae spasticity in spinal cord injury. Arch Phys Med Rehabil. 2006;87(2):222-28. [PMID:16442976] http://dx.doi.org/10.1016/j.apmr.2005.09.024

70. Frasson E, Priori A, Ruzzante B, Didonè G, Bertolasi L. Nerve stimulation boosts botulinum toxin action in spasticity. Mov Disord. 2005;20(5):624-29. [PMID:15726575] http://dx.doi.org/10.1002/mds.20395

71. Baricich A, Carda S, Bertoni M, Maderna L, Cisari C. A single-blinded, randomized pilot study of botulinum toxin type A combined with non-pharmacological treatment for spastic foot. J Rehabil Med. 2008;40(10):870-72. [PMID:19242626]

72. Picelli A, Smania N, Storti I, Munari D, Fontana C, Fiaschi A, Santilli V, Tamburin S. Immediate versus delayed electrical stimulation boosts botulinum toxin effect: A pilot study. Mov Disord. 2011;26(9):1784-85.

[PMID:21538521]

http://dx.doi.org/10.1002/mds.23678

Submitted for publication March 8, 2012. Accepted in revised form July 24, 2012.

This article and any supplementary material should be cited as follows:

Wilkenfeld AJ. Review of electrical stimulation, botulinum toxin, and their combination for spastic drop foot. J Rehabil Res Dev. 2013;50(3):315-26.

http://dx.doi.org/10.1682/JRRD.2012.03.0044

ResearcherID/ORCID: Ari Jacob Levi Wilkenfeld, MD, PhD: D-6366-2013

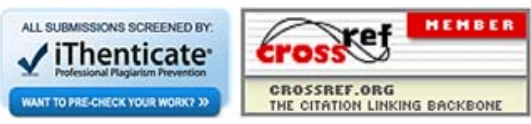

